\title{
The lack of Lazarus effect with proteasome inhibition
}

\author{
Stephen D. Marks ${ }^{1}$
}

Received: 5 January 2016 / Accepted: 6 January 2016 /Published online: 5 April 2016

(C) IPNA 2016

\begin{abstract}
There have been marked improvements in the short- and long-term outcomes for children after renal transplantation over the past two decades with superior quality and quantity of life. It is encouraging to see increased patient and renal allograft survival rates with initially lower acute renal allograft rejection rates due to improved matching and immunosuppressive regimens. Unfortunately, longer-term renal allograft survival remains unchanged with chronic allograft injury from both immune and non-immune causes, resulting in chronic allograft dysfunction, morbidity from chronic kidney disease, and eventual renal allograft loss. Acute and chronic antibody-mediated rejection remains a clinical dilemma with a growing evidence base of its treatment, including proteasome inhibition using intravenous bortezomib. The future goal is to reduce chronic allograft dysfunction and make renal transplants last longer for pediatric renal transplant recipients who may require retransplantation during their childhood and adult lives, which can become successively more difficult due to sensitization.
\end{abstract}

Keywords Renal transplantation · Renal allograft survival · Antibody-mediated rejection · Donor-specific antibodies . Bortezomib $\cdot$ Proteasome inhibition

Stephen D. Marks

stephen.marks@gosh.nhs.uk

1 Department of Paediatric Nephrology, Great Ormond Street Hospital for Children NHS Foundation Trust, Great Ormond Street, London WC1N 3JH, England, UK

\section{Introduction}

Pre-emptive living-related renal transplantation is now the gold-standard therapy for children with end-stage kidney disease (ESKD), with increased renal allograft survival in the first month and first year after renal transplantation due to improvements in both surgical techniques and medical management (prophylaxis and treatment of acute allograft rejection as well as reduced renal allograft thrombotic rates) [1]. Due to enhanced immunosuppressive therapies, there has been a reduction in acute renal allograft rejection in the first year after transplantation from $53 \%$ and $67 \%$ in 1987 to $9 \%$ and $14 \%$ in 2013 for living and deceased donors, respectively [2].

Many groups have studied that the main causes for the progressive decline in renal function leading to renal allograft loss and the requirement for chronic dialysis and/or re-transplantation is acute and chronic antibody-mediated rejection (AMR), with the development of post-transplant de novo donor-specific antibodies (DSA) produced by B cells developing high-affinity receptors targeting HLA mismatches arising from the graft [3]. However, complement activation is required to cause renal allograft dysfunction and injury in renal transplant recipients (RTR) with de novo DSA and may not always be related to the threshold level but the stepwise change of mean fluorescence intensity (MFI) of the DSA [4].

\section{Treatment of antibody-mediated rejection}

There are currently several therapeutic strategies available to treat AMR (Table 1). However, in clinical practice, these therapies are usually used in combination, with variable success [5]. Intravenous bortezomib is a proteasome inhibitor that has a direct effect by inducing apoptosis in mature plasma cells 
Table 1 Strategies to treat antibody-mediated rejection

\begin{tabular}{ll}
\hline Agent & Reason \\
\hline $\begin{array}{l}\text { Non-specific immunosuppressive } \\
\text { augmentation } \\
\text { Plasmapheresis }\end{array}$ & Reduce DSA \\
& $\begin{array}{c}\text { Remove pre-formed } \\
\text { DSA from circulation }\end{array}$ \\
Intravenous immunoglobulin & $\begin{array}{c}\text { Modulate immune } \\
\text { response to DSA }\end{array}$ \\
Intravenous eculizumab & $\begin{array}{c}\text { Inhibit complement activation } \\
\text { resulting from }\end{array}$ \\
& Ag-Ab complex formation \\
Intravenous rituximab & B cell depletion \\
Intravenous bortezomib & Induces apoptosis in \\
& mature plasma cells \\
\hline
\end{tabular}

$D S A$ donor-specific antibodies

that synthesize the pathogenic antibodies that can cause renal allograft injury. It is currently approved to treat patients with multiple myeloma and mantel cell lymphoma.

In an article recently published in Pediatric Nephrology, Pearl and colleagues have reported a retrospective case series on the safety and efficacy of between one and three rounds, each of four doses of bortezomib $1.3 \mathrm{mg} / \mathrm{m}^{2} /$ dose (days $1,4,8$, and 15 ) in seven pediatric and adolescent RTR aged 5 to 19 years with treatment refractory C4d+AMR between 1 and 145 (median 65 ) months post-transplantation [6]. However, it should be noted that all but one case had between six and eight HLA A, B, DR, and DQ mismatches (the final DQ may be added to routine HLA matching in the future) and the only case of renal allograft loss was the case with pre-formed DSA. These recipients were all treated with thymoglobulin, basiliximab, or daclizumab induction with the majority (six) having adherence issues to triple immunosuppression (with prednisolone, mycophenolate mofetil, and tacrolimus in five cases).

How can we be sure that any stabilization of renal allograft function by estimated glomerular filtration rate (eGFR) or survival is due to bortezomib when these patients were treated with additional therapies? These included intravenous rituximab $375 \mathrm{mg} / \mathrm{m}^{2}$ (day 1), plasmapheresis performed on days 1, 4, 8, 15, 17, 19, and 22 (immediately prior to bortezomib administration on days 1,4 , 8 , and 15) and intravenous immunoglobulin $1 \mathrm{~g} / \mathrm{kg}$ on the last day of treatment (day 22) per each round of treatment.

Five cases $(72 \%)$ had two rounds of treatments (with one case each of one and three treatment rounds). Of the six patients with surviving grafts $(86 \%)$, the mean pre-bortezomib eGFR was $42 \mathrm{ml} / \mathrm{min} / 1.73 \mathrm{~m}^{2}$ and the mean 1-year post-bortezomib eGFR was $53 \mathrm{ml} / \mathrm{min} / 1.73 \mathrm{~m}^{2}$. Five of seven (71\%) had improvement of histological findings of AMR, C4d staining, and/or acute cellular rejection, although the reduction in DSA was more effective for HLA Class I than HLA Class II.

However, I am left wondering which treatment or combination of treatments were successful (or not) in treating AMR in this small series of children. The patients were not treated as part of a prospective clinical trial, as the authors state that this was a retrospective case review without formal ethics committee approval or patient consent.

At present, there is a lack of the Lazarus effect in the use of bortezomib in adult liver and renal transplant recipients with acute AMR, which may be reversible in isolated cases [7, 8]. Bortezomib may reduce DSA, but is not always effective in treating AMR [9]. However, there need to be randomized controlled prospective clinical trials using bortezomib for treating acute and chronic AMR as well as in desensitization protocols for highly sensitized patients, as this therapy may reduce DSA levels (even in the absence of AMR) and prolong renal allograft survival by protecting transplants from chronic allograft injury and dysfunction. Bortezomib may have a role with other agents in combination as part of desensitization for patients awaiting transplantation or re-transplantation, as bortezomib preconditioning alone does not result in a sustained reduction of HLA antibody levels in all patients [10], so some centers have used combination therapies of bortezomib with eculizumab in this setting [11].

\section{Conclusions}

The optimal therapy for treating AMR with or without renal allograft dysfunction remains elusive, as RTR may have one or more features with detection of DSA in the peripheral circulation or presence of AMR on renal transplant biopsy with or without $\mathrm{C} 4 \mathrm{~d}$ deposition in the peritubular capillaries. We currently cannot predict which patients with DSA will develop AMR and chronic allograft injury and dysfunction, so collaborative research is required to define the optimal biomarkers of renal allograft injury prior to the development of renal allograft dysfunction [12]. In the next few years, there should be results from multi-center randomized controlled trials in pediatric and adult RTR to answer the questions if bortezomib has a role in RTR with high titer DSA prior to the development of AMR and in those with early or late established AMR as well as an induction agent in sensitized RTR. The infectious, neurological, hematological, and gastrointestinal side-effect profile of bortezomib needs to be studied in pediatric as well as adult RTR.

Acknowledgments This project was supported by the National Institute for Health Research Biomedical Research Centre at Great Ormond Street Hospital for Children NHS Foundation Trust and University College London.

\section{Compliance with ethical standards}

Conflict of interest The author(s) declare that they have no competing interests 


\section{References}

1. Kim JJ, Marks SD (2014) Long-term outcomes of children after solid organ transplantation. Clinics 69(21):22-27

2. North American Pediatric Renal Trials and Collaborative Studies (2014) Annual Transplant Report. [accessed 5 January 2016]; Available from: https://web.emmes.com/study/ped/annlrept/ annualrept2014.pdf

3. Kim JJ, Balasubramanian R, Michaelides G, Wittenhagen P, Sebire NJ, Mamode N, Shaw O, Vaughan R, Marks SD (2014) The clinical spectrum of de novo donor-specific antibodies in pediatric renal transplant recipients. Am J Transplant 14(10):2350-2358

4. Comoli P, Cioni M, Tagliamacco A, Quartuccio G, Innocente A, Fontana I, Trivelli A, Magnasco A, Nocco A, Klersy C, Rubert L, Ramondetta M, Zecca M, Garibotto G, Ghiggeri GM, Cardillo M, Nocera A, Ginevri F (2016) Acquisition of C3d-binding activity by de novo donor-specific HLA antibodies correlates with graft loss in non-sensitised pediatric kidney recipients. Am J Transplant. doi:10. 1111/ajt. 13700

5. Kim JJ, Jones HE, Marks SD (2012) Long-term outcomes of rituximab for antibody-mediated rejection in paediatric renal transplant recipients. Pediatr Nephrol 27(9):1819

6. Pearl MH, Nayak AB, Ettenger RB, Puliyanda D, Diaz MFO, Zhang Q, Reed EF, Tsai EW (2016) Bortezomib may stabilise pediatric renal transplant recipients with antibody-mediated rejection. Pediatr Nephrol. doi:10.1007/s00467-016-3319-3
7. Lee CF, Eldeen FZ, Chan KM, Wu TH, Soong RS, Wu TJ, Chou HS, Lee WC (2012) Bortezomib is effective to treat acute humoral rejection after liver transplantation. Transplant Proc 44:529-531

8. Gupta G, Abu Jawdeh BG, Racusen LC, Bhasin B, Arend LJ, Trollinger B, Kraus E, Rabb H, Zachary AA, Montgomery RA, Alachkar N (2014) Late antibody-mediated rejection in renal allografts: outcome after conventional and novel therapies. Transplantation 97(12):1240-1246

9. Cicora F, Pas M, Mos F, Roberti J (2013) Use of bortezomib to treat anti-HLA antibodies in renal transplant patients: a single-center experience. Transpl Immunol 29(1-4):7-10

10. Guthoff M, Schmid-Horch B, Weisel KC, Häring HU, Königsrainer A, Heyne N (2012) Proteasome inhibition by bortezomib: effect on HLA-antibody levels and specificity in sensitized patients awaiting renal allograft transplantation. Transpl Immunol 26:171-175

11. Lonze BE, Dagher NN, Simpkins CE, Locke JE, Singer AL, Segev DL, Zachary AA, Montgomery RA (2010) Eculizumab, bortezomib and kidney paired donation facilitate transplantation of a highly sensitized patient without vascular access. Am J Transplant 10:2154-2160

12. Plotnicki L, Kohl CD, Höcker B, Krupka K, Rahmel A, Pape L, Hoyer P, Marks SD, Webb N, Söylemezoglu O, Topaloglu R, Attila S, Seeman T, Cornelissen EAM, Knops N, Grenda R, Tönshoff B (2013) The CERTAIN registry: a novel, web-based registry and research platform for pediatric renal transplantation in Europe. Transplant Pro 45(4):14141417 